Research Article

\title{
Real-Time Low-Cost Speed Monitoring and Control of Three-Phase Induction Motor via a Voltage/Frequency Control Approach
}

\author{
Ali Hmidet $\left(^{1}{ }^{1}\right.$ and Olfa Boubaker $\left(^{2}\right.$ \\ ${ }^{1}$ Tunis El Manar University, ISTMT, Tunis, Tunisia \\ ${ }^{2}$ Carthage University, National Institute of Applied Sciences and Technology, Tunis, Tunisia \\ Correspondence should be addressed to Ali Hmidet; hmidetali@yahoo.fr
}

Received 1 January 2020; Accepted 14 March 2020; Published 22 April 2020

Guest Editor: Mohamed Nayel

Copyright (c) 2020 Ali Hmidet and Olfa Boubaker. This is an open access article distributed under the Creative Commons Attribution License, which permits unrestricted use, distribution, and reproduction in any medium, provided the original work is properly cited.

In this paper, a new design of a real-time low-cost speed monitoring and closed-loop control of the three-phase induction motor (IM) is proposed. The proposed solution is based on a voltage/frequency (V/F) control approach and a PI antiwindup regulator. It uses the Waijung Blockset which considerably alleviates the heaviness and the difficulty of the microcontroller's programming task incessantly crucial for the implementation and the management of such complex applications. Indeed, it automatically generates $\mathrm{C}$ codes for many types of microcontrollers like the STM32F4 family, also used in this application. Furthermore, it offers a cost-effective design reducing the system components and increasing its efficiency. To prove the efficiency of the suggested design, not only simulation results are carried out for a wide range of variations in load and reference speed but also experimental assessment. The real-time closed-loop control performances are proved using the aMG SQLite Data Server via the UART port board, whereas Waijung WebPage Designer (W2D) is used for the web monitoring task. Experimental results prove the accuracy and robustness of the proposed solution.

\section{Introduction}

During the last decades, induction motor (IM) drives are becoming more and more popular in industrial applications as well as in home appliances, thanks to their reliability, low cost, robustness, ease of maintenance, and simplicity of control $[1-3]$.

The control methods of IM are mainly classified into two major classes: scalar control and vector control approaches [4-6]. Scalar control, popularly known as voltage/frequency $(\mathrm{V} / \mathrm{F})$ control, is considered as a simple approach based on the control of the supply voltage amplitude and the frequency. For indirect control of the IM speed, it uses a threephase voltage source inverter (VSI) controlled by a pulse width modulation (PWM) technique. However, despite its simplicity of implementation, scalar control methods cannot achieve best performances during transients, which is considered as a major disadvantage $[1,7,8]$.
Vector control approaches, also known as field-oriented control (FOC) approaches, allow not only the control of the amplitude and frequency of the voltage as it is the case for scalar control approaches but also the instantaneous position of the flux, the voltage vectors, and the current vectors $[9,10]$. They are considered as mathematical model-based approaches. Especially in the transient regime, they guaranty better control performances compared to the scalar control approaches. Unfortunately, such control methods have complex algorithms and require a lot of computation time [11-13].

As the simplicity of the control algorithm is of major interest for users, the scalar control approach is still considered as the most used in industrial applications, especially when accuracy of the speed response in the transient regime is not mandatory, such as for ventilation and air conditioning applications and heating and pumping systems [13-15]. The objective of these methods is to control the IM 
speed by maintaining constant stator flux. The magnitude of the stator flux is proportional to the ratio between the stator voltage and the frequency. However, if this ratio is kept constant, the flux remains constant. Also, by keeping V/F constant, the developed torque remains approximately constant. This method gives higher run-time efficiency $[16,17]$. Therefore, most AC speed drives (ACSD) employ the constant V/F method for the speed control. Along with the wide range of speed control, this method also offers "soft start" capability $[18,19]$.

On the contrary, the great progress in microcontrollers and the power electronic components became an important factor in variable speed drive processing [20-22]. STM32F4 family of microcontrollers, for example, offers high-quality performances at the service of high-performance variable speed drives. Programming microcontrollers for such heavy and complex applications with conventional languages (such as assembler, $C$, or $C++$ languages) increase the scaling time of such applications. It requires, furthermore, the availability of an expert in computer programming with in-depth knowledge of processor architecture. In addition, in order to reduce operating costs and enhance the reliability and safe security of the proposed design, industrial applications should be monitored in real-time which allows perfect control and system supervision. Real-time monitoring has become consequently a major task for engineers and researchers in industrial applications such as pumping, mining industry, railways, and industrial drives. [23-25].

In this work, we propose a new design of a real-time low-cost speed monitoring and closed-loop control of the three-phase induction motor. The control system, operating according to the rule $\mathrm{V} / \mathrm{F}$ constant, is developed using VSI based on a space vector pulse width modulation (SVPWM) technique and a three-phase IM loaded by a magnetic power breaker. Waijung is also designed to solve this problem. It is a Simulink Blockset that can be used as targets to easily and automatically generate $\mathrm{C}$ code from Matlab/Simulink simulation models for STM32F4 Discovery microcontroller. The real-time speed monitoring and control of the proposed algorithm are done in two different ways. The first is based on the COM/UART port and USB converter, and the second manner uses Waijung WebPage Designer (W2D). Hardware required for this application is grouped as aMG Labkit F4N, suitable for many industrial applications. To our best knowledge, such solutions have never been previously tested for ACSD despite the significance of the solution. Furthermore, performance evaluation of the proposed algorithm will be verified not only via computer simulation results but also via experimental assessment for a wide range of variations in load and reference speed.

This paper is structured as follows. Section 2 presents the mathematical model of the three-phase IM and the related drive system. Section 3 presents the designed scalar control approach for closed-loop control of the IM. In Section 4, the effectiveness of the proposed approach is proved via simulation results. Finally, Section 5 expands experimental results for different scenarios.

\section{Process Mathematical Modeling}

2.1. The Induction Motor. The electrical machine considered in this paper is a three-phase squirrel-cage (short-circuit rotor) asynchronous machine. The main electrical equations in the stationary reference frame can be written by the following form [7-9]:

$$
\begin{gathered}
\frac{d \bar{\varphi}_{s}}{d t}=\bar{v}_{s}-R_{s} \bar{i}_{s}, \\
\frac{d \bar{\varphi}_{r}}{d t}=j \omega_{r} \bar{\varphi}_{r}-R_{r} \bar{i}_{r}, \\
\bar{\varphi}_{s}=\ell_{s} \bar{i}_{s}+m \bar{\varphi}_{r}, \\
T_{e m}-K_{f} \omega_{r}-T_{r}=\frac{j}{p} \frac{d \omega_{r}}{d t} .
\end{gathered}
$$

In the previous set of equations, $\bar{v}_{s}$ is the stator voltage vector per phase and $\bar{\varphi}_{s}$ and $\bar{\varphi}_{r}$ represent the stator/rotor flux, respectively. The stator/rotor currents are denoted by $\bar{i}_{s}$ and $\bar{i}_{r} . R_{s}$ and $R_{r}$ are the stator/rotor resistances, respectively. $\ell_{s}$ and $m$ are leakage inductance and the ratio between mutual inductance $M$ and rotor inductance $L_{r}$, respectively. Electrical speed and the number of pole pairs are denoted by $\omega_{r}$ and $p$, respectively. Various expressions can be used to calculate electromagnetic torque $T_{e m}$. The most used relation is described by equation (4), where $K_{f}$ is the viscous coefficient, $j$ is the moment of inertia, and $T_{r}$ is the load torque.

2.2. The Induction Motor Drive. Figure 1 describes the association between a three-phase voltage converter and the IM. The power circuit of the converter is basically composed of three modules, namely, the three-phase rectifier, the $\mathrm{AC} /$ DC filter capacitor, and three-phase inverter, whereby $\mathrm{D}_{1}-\mathrm{D}_{6}$ are the three-phase rectifier diode circuit, $\mathrm{C}$ is the filter capacitor DC bus, and $\mathrm{C}_{1}-\mathrm{C}_{6}$ are the power switches. A three-phase source inverter, whose objective is to provide variable voltage and variable frequency output through pulse width modulation (PWM) control, drives the IM [26]. Several PWM techniques can be used to generate signal command for the voltage inverter $[13,15,19]$. In this work, we use the SVPWM technique.

2.3. Space Vector Pulse Width Modulation Technique. Considering a lossless three-phase inverter, the output voltage is obtained according to the DC bus voltage $\mathrm{Vdc}$ and the logic state of the three highest switches $(\mathrm{C} 1, \mathrm{C} 2, \mathrm{C} 3)$. Thus, there are eight possible logical combinations of $(\mathrm{C} 1$, $\mathrm{C} 2, \mathrm{C} 3)$ leading to six active voltage vectors and two null voltage vectors. The space vector of the output voltage of the inverter can be expressed by the following expression:

$$
\bar{v}_{k}= \begin{cases}\sqrt{\frac{2}{3}} V_{d c} e^{j(k-1)(\pi / 3)}, & \text { for } k=1, \ldots, 6, \\ 0 & \text { for } k=0,7,\end{cases}
$$




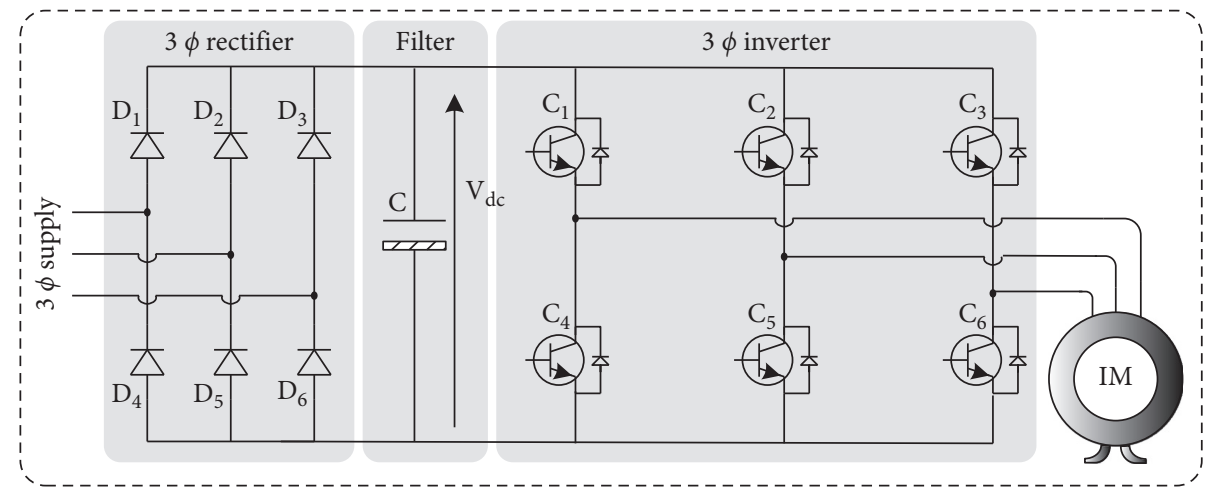

Figure 1: Association of power modules for the three-phase voltage converter-IM.

where $k$ is an integer indicating the switching combinations $[13,26]$. In the complex plane $\mathrm{d}-\mathrm{q}$, different voltage vectors delivered by the inverter and the associated combinations of the switches $\mathrm{C} 1, \mathrm{C} 2$, and $\mathrm{C} 3$ are given by Figure 2.

The goal of SVPWM is to produce a mean voltage vector during the PWM period $\left(T_{s}\right)$ that is equal to the desired voltage vector $\bar{v}_{\text {ref }}$. This is done by applying the neighboring vectors $\bar{v}_{k}$ for a specified time $\left(\tau_{k}\right), \bar{v}_{k+1}$ for a specified time $\left(\bar{v}_{k+1}\right)$, and the null vector $\bar{v}_{0}$ or $\bar{v}_{7}$ for the amount of time necessary $\tau_{0}$. Thereby, to obtain an average value which equals to $\bar{v}_{r e f}$ over the period $T_{s}$, we must have the following relation:

$$
\frac{\tau_{k} \cdot \bar{v}_{k}+\tau_{k+1} \cdot \bar{v}_{k+1}}{T_{s}}=\bar{v}_{\text {ref }} .
$$

The values of $\tau_{k}, \tau_{k+1}$, and $\tau_{0}$ can be computed using the following equations:

$$
\left\{\begin{array}{l}
\tau_{k}=T_{s} \rho \sin \left(\left(\frac{\pi}{3}\right)-\varsigma\right), \\
\tau_{k+1}=T_{s} \rho \sin (\varsigma), \\
\tau_{0}=T_{s}-\tau_{k}-\tau_{k+1}, \\
\rho=\frac{\sqrt{2} V_{r e f}}{V_{d c}}
\end{array}\right.
$$

where the coefficient $\rho$ designates a voltage ratio.

To respect the condition of $\tau_{k}+\tau_{k+1} \leq T_{s}$, the module $V_{\text {ref }}$ of the requested voltage $\bar{v}_{\text {ref }}$ should verify the following condition:

$$
V_{\text {ref }} \leq \frac{V_{d c}}{\sqrt{2}}
$$

It should be noted here that the condition given by condition (6) related to the feasibility of the synthesis is established by considering a voltage vector in the Concordia reference frame, which implies that the magnitude $V_{\text {ref }}$ used corresponds to either $\sqrt{3}$ times the rms value or $\sqrt{3 / 2}$ times the maximum value in the natural system.

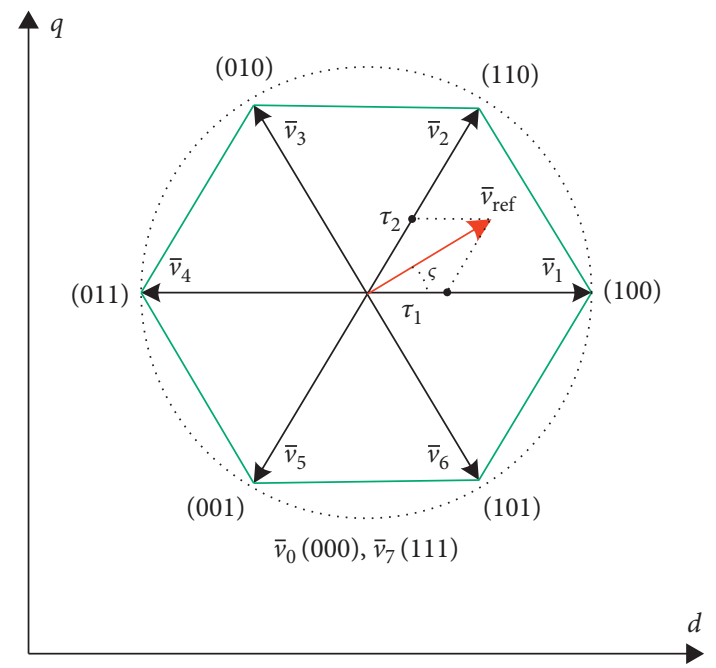

FIGURE 2: Inverter voltage vectors in Concordia's reference frame.

\section{Scalar Control Design}

The scalar control methodology focuses only on the steady state dynamic, allows to adjust the supply voltage as well as its frequency so that their ratio remains constant in order to avoid magnetic flux saturation, and affects the available torque of the machine $[7,8]$. Starting from equation (1) and assuming that the voltage drop across the stator resistance is small in comparison with the stator voltage mainly at the low-slip regions, the stator flux $\Phi_{s}$ can be expressed as $[12,16]$

$$
\Phi_{s} \approx \frac{V_{s}}{2 \Pi f_{s}},
$$

where $V_{s}$ is the stator voltage magnitude and $f_{s}$ is the supply frequency $(\mathrm{Hz})$. The electromagnetic torque-slip characteristic in the stationary regime takes the following form [6]:

$$
T_{e m}=3 p \frac{R_{r}}{g} \frac{V_{s}^{2}}{\omega_{s}} \frac{1}{\left(R_{r} / g\right)^{2}+X_{l r}^{2}},
$$

where $g$ is the slip and $R_{r}$ and $X_{l r}$ represent the rotor resistance and total leakage reactance located in the rotor, respectively. 
In the low-slip region (normal operating conditions), the above equation is simplified by

$$
T_{e m}=3 \frac{p}{R_{r}} \Phi_{s}^{2} g \omega_{s}
$$

This implies that if the stator flux is maintained constant, the variation of the torque as a function of the slip is almost linear.

Frequency control is natural for adjustable speed drive applications. However, voltage is required to be proportional to frequency so that the stator flux remains constant if the stator resistance is neglected. The open-loop V/F control of an IM is one of the most common methods widely used in the industry due to its simplicity, low cost, and performance drive [27]. As the rotor speed $\omega_{r}$ will be slightly less than the synchronous speed $\omega_{s}$ as a result of the slip speed $\omega_{g}$, the speed of the motor cannot be controlled accurately. Also, as the rotor speed is not measured in this schema, the slip pulsation cannot be maintained. Consequently, the operation in the unstable area of the torquespeed characteristics can take place. Equally, the stator currents can exceed greatly the nominal current under the effect of the point mentioned above and thus endangers the combination inverter machine. These drawbacks should have solutions by making an outer control loop in the IM drive, where the actual rotor speed $\omega_{r}$ should be compared with a reference value $\omega_{\text {ref }}$, and hence, the error between these variables is generated [16-18]. This error is processed through a PI controller and a limiter to get the slip-speed command $\omega_{g}$. The inverter frequency command $\omega_{\text {sref }}$ is generated by adding the slip command $\omega_{g}$ and the actual speed signal $\omega_{r}$, and the frequency command generates the voltage command $V_{s}$ or its voltage ratio $\rho$ through a volt/ hertz function generator. The resulting $\omega_{\text {sref }}$ and $\rho$ are applied to the motor by means of an SVPWM-VSI.

In low-speed operation, the voltage drop in the stator resistance is not negligible compared to that in the leakage reactance. Inversely, in the operation at a speed greater than that corresponding to the nominal frequency, a weakening of the magnetic field is led. In order to avoid these anomalies, the $\mathrm{V} / \mathrm{F}$ control structure should then consider the voltage drop in the resistance at the low speed to maintain a constant stator flux, and it must limit the voltage when the nominal frequency is reached. The input voltage is then adjusted according to the frequency required to a specific speed reference as shown by the following equation $[12,16,21]$ :

$$
V_{s}= \begin{cases}\left(V_{s n}-V_{0}\right) \frac{f}{f_{n}}+V_{0}, & \text { for } f<f_{n}, \\ V_{s n}, & \text { for } f \geq f_{n} .\end{cases}
$$

A control scheme of the V/F and slip regulation-controlled IM is shown in Figure 3.

For a better performance of the conventional scalar control, an antiwindup PI regulator is used. The antiwindup PI controller is an improvement of the classical PI control. The use of antiwindup strategy is to prevent the

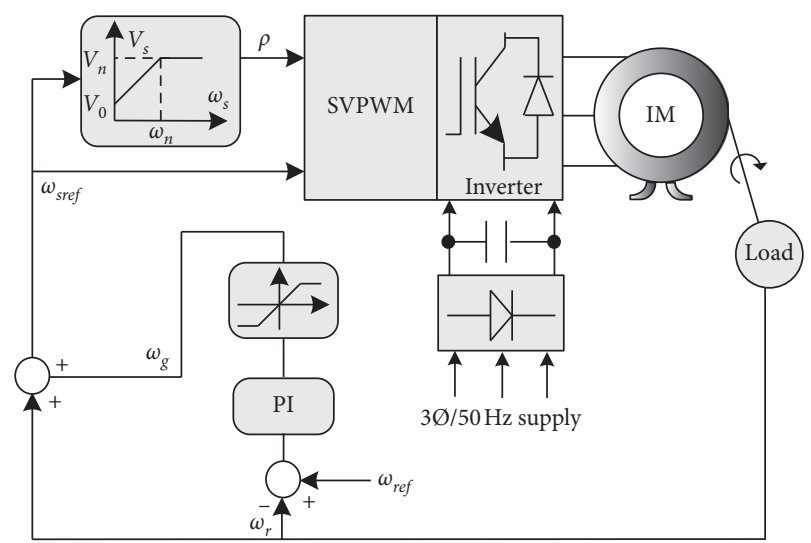

Figure 3: Closed-loop scalar control scheme.

controller from going into deep saturation and inspect the windup controller output when large set-point changes are made. This helps to prevent extreme overshoot during the startup of the IM and guarantees the desired performance independent of the operating conditions, i.e., reference variations and load torques [8,20]. Figure 4 shows the block diagram of a PI controller where the difference between the output value and the input value of the saturation block is used as a feedback signal through a gain $(1 / \mathrm{Tt})$ to forward the input to the integrator.

\section{Simulation Results}

To analyze and verify the performances of the proposed solution, the control methodology shown by Figure 3 is carried out by using MATLAB/Simulink software for the technical specifications of the IM which is given by Table 1 . Simulation results are conducted for various operating conditions. Two main scenarios are given here: speed response under crenel variations of load torque and speed response under crenel variations of reference speed. The sampling time used in all simulation is $100 \mu \mathrm{s}$.

4.1. Scenario 1: Speed Response under Crenel Load Torque Variations. In this test, a signal reference of $150 \mathrm{rad} / \mathrm{s}$ which is equal to nominal speed is used. A variation by crenels of the load torque is applied going from zero to the nominal torque: 0 at $5 \mathrm{~s}, 3 \mathrm{Nm}$ at $10 \mathrm{~s}, 6.82 \mathrm{Nm}$ at $20 \mathrm{~s}, 3 \mathrm{Nm}$ at $30 \mathrm{~s}$, and 0 at $40 \mathrm{~s}$. Figures $5-9$ show the obtained simulation results. These figures show that the proposed algorithm operates perfectly, and the antiwindup PI controller offers the best response. Figure 5 shows that the speed response is coincident with its reference. This is confirmed by Figure 6 showing a zoom on Figure 5. The speed response is practically perfect with no overshoot and an insignificant delay. Figures 7 and 8 show the response of the stator voltage. The voltage ratio varies as a function of the reference speed and proportional to the stator pulsation verifying that the flux is constant as the main property of scalar control. Figure 9 gives the stator and rotor pulsations and confirms that the slip pulsation (difference between stator and rotor pulsations) is proportional to the load torque as mentioned 


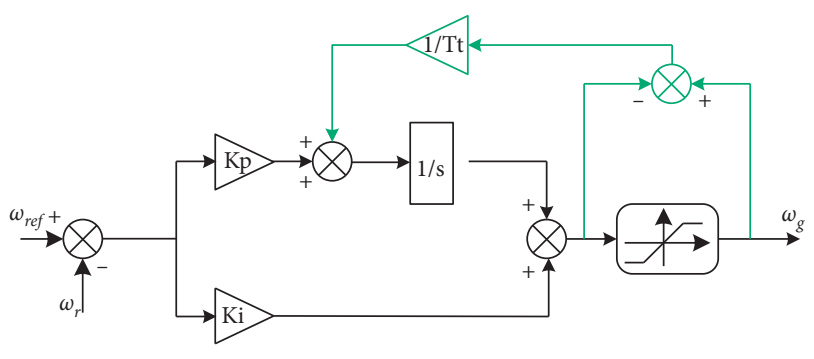

FIgURE 4: Speed regulation using the PI antiwindup controller.

TABle 1: Motor data.

\begin{tabular}{lc}
\hline Parameter designation & Parameter value \\
\hline Stator resistance & $R_{s}=7.5 \Omega$ \\
Rotor resistance & $R_{r}=6.5 \Omega$ \\
Principal stator inductance & $L_{s}=354 \mathrm{mH}$ \\
Principal rotor inductance & $L_{r}=354 \mathrm{mH}$ \\
Mutual inductance & $M=340 \mathrm{mH}$ \\
Number of pole pairs & $p=2$ \\
Rated frequency & $50 \mathrm{~Hz}$ \\
Rated electrical speed & $293.22 \mathrm{rad} / \mathrm{s}$ \\
Rated power & $1 \mathrm{KW}$ \\
Rated voltage & $220 / 380 \mathrm{~V}$ \\
Rated power factor & 0.78 \\
\hline
\end{tabular}

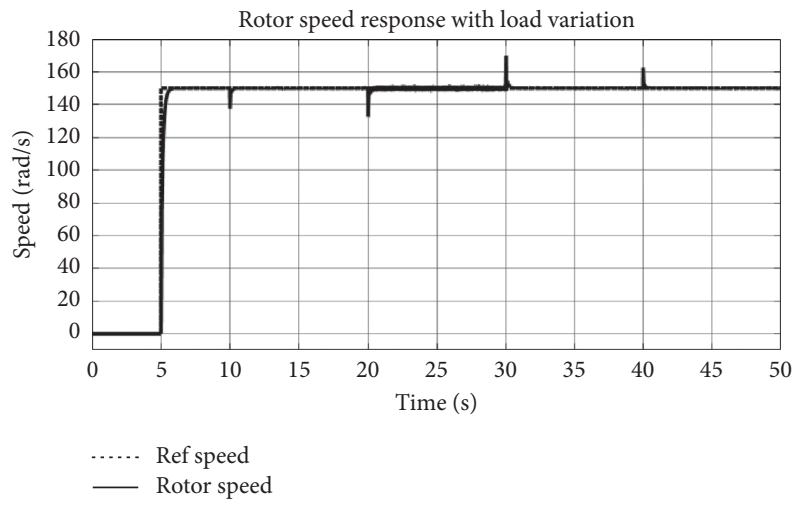

FIGURE 5: Speed response under load torque variation.

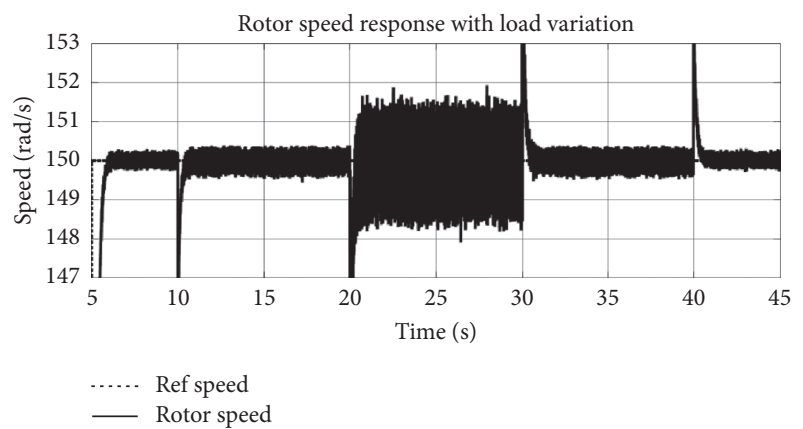

FIGURE 6: Steady state operation (zoom on Figure 5).

previously by equations (10) and (11). In Figure 9, the slip pulsation is between 0 (without load) and $30 \mathrm{rad} / \mathrm{s}$ (in nominal operating condition).

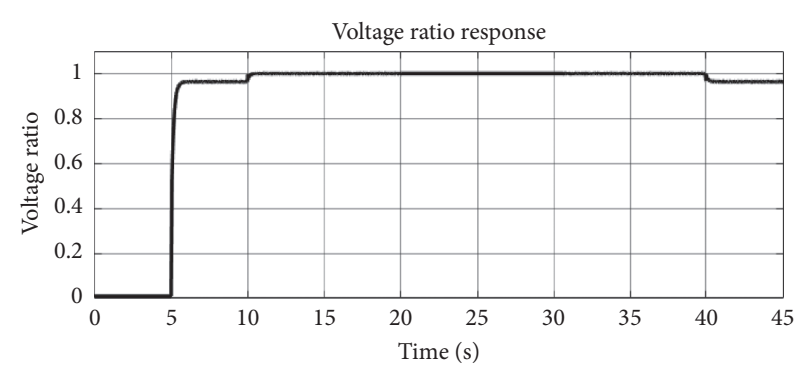

Figure 7: Voltage ratio response under load torque variation.

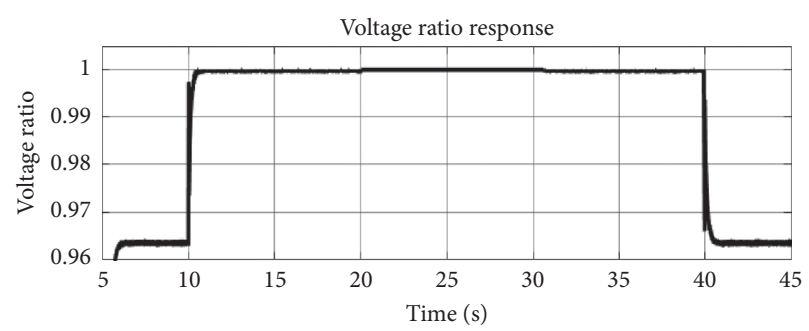

Figure 8: Zoom on Figure 7 (ratio $96.5 \%$ for IM without load, 98\% for $3 \mathrm{Nm}$, and $100 \%$ for $6.82 \mathrm{Nm}$ ).

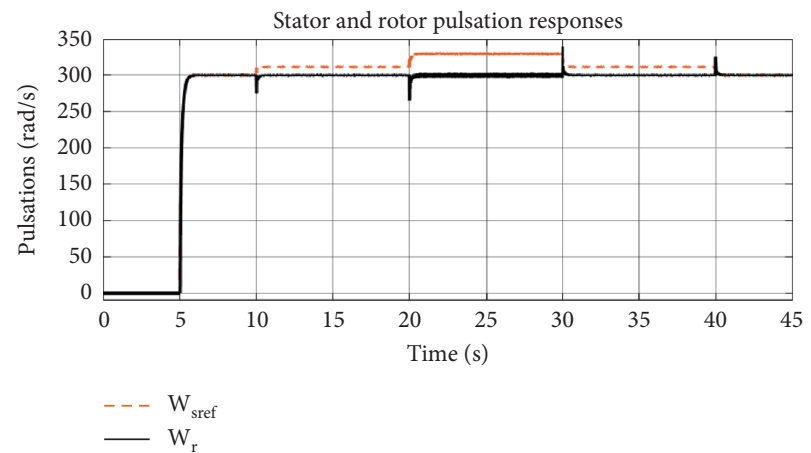

FIGURE 9: Stator and rotor pulsation responses under load torque variation.

4.2. Scenario 2: Speed Response under Reference Speed Variations. This simulation test performs the effects of the variations of the reference on the speed control. Figure 10 presents the rotor speed response under a reference speed crenel variation starting from 0 , then $100,120,157,150$, and 80 , and returns to $0 \mathrm{rad} / \mathrm{s}$. In Figure 10 , the rotor speed follows perfectly its reference. The IM is operated without load; thus, the stator and rotor pulsations are equal, so the slip is zero. Figure 11 shows the stator voltage represented by its ratio. It is easy to check here that the V/F constant is confirmed because the stator voltage-pulsation trajectories have the same form.

\section{Experimental Validation}

In this section, experimental results related to the real-time monitoring and control of the IM speed will be carried out via two communication techniques. For the first one, the communication is realized via the UART port, where for the second, the Waijung WebPage Designer (W2D) is exploited. 


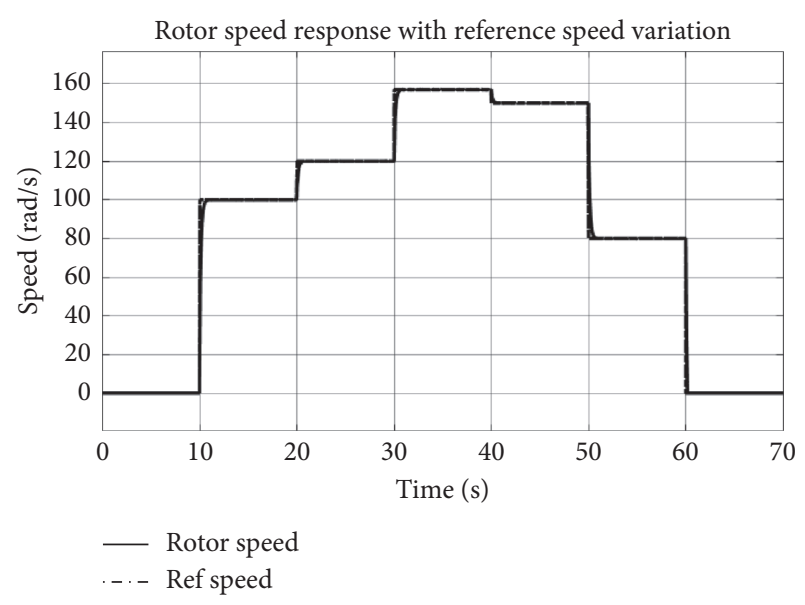

Figure 10: Speed response under reference speed variation.

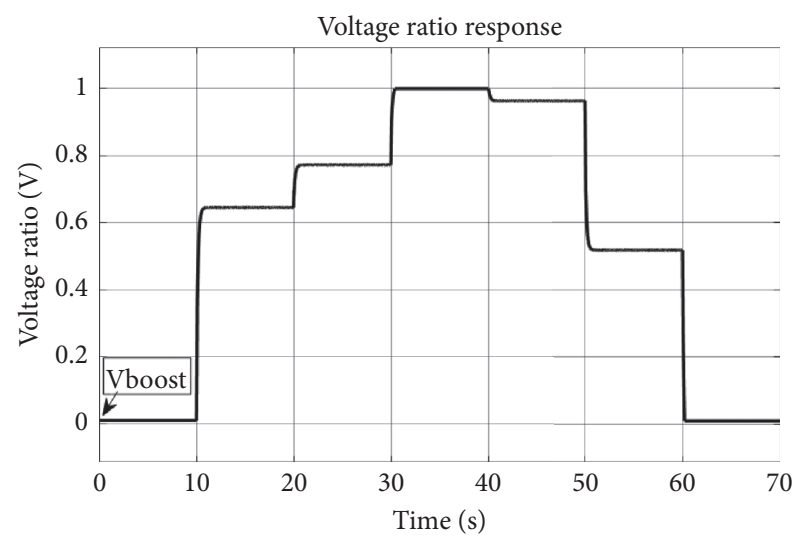

FigURE 11: Voltage ratio response under reference speed variation.

Furthermore, for each technique, the experimental results are carried out for the two scenarios considered in simulation results.

The test bench [28] used for validation is built around an aMG labkit F4-based STM32F4 discovery. The aMG Labkit F4 [29] consists of low-cost high-performance DSP hardware with a variety of Plug-n-Play modules. This kit is supported by the Matlab/Simulink toolkit with Waijung Blockset and Waijung WebPage Designer (Drag and Drop Web-based Monitoring and Control) [30]. The photo of Figure 12 shows the main hardware components used in our application, including the following:

(i) aMG F4 Connect 2 as the shield to enable various add-on expansion boards cited below

(ii) aMG SQLite Database Server for the embedded database

(iii) aMG USB Converter-N2 (Converter-N Adapter) for real-time hardware in the loop simulation

(iv) aMG Ethernet INF for the LAN interface

(v) aMG CAN INF for the CAN Bus Interface

(vi) STM32F4 DISCOVERY Kit which is a low-cost development kit from STMicroelectronics
The overall test bench is shown in Figure 13. It includes in addition the following:

(i) A squirrel-cage IM with parameters given in Table 1 .

(ii) A magnetic powder breaker as the load for the IM.

(iii) Omron incremental encoder having 360 pulses per revolution coupled to the machine shaft.

(iv) A Semikron converter based on the three-phase rectifier, a DC Bus filter, and the three-phase inverter. The inverter is used to drive the IM.

(v) A 2 channel, $20 \mathrm{MHz}$ analog oscilloscope for visualization.

(vi) Sensors for current and voltage measurement, types LEM LA25-NP and LEM LV25-P, respectively.

The ST microcontroller TM32F4VG407 Discovery controller generates the main program. It ensures the measurement of the rotor speed via an incremental encoder, achieving the control algorithm (V/F) including a PI antiwindup regulator and the generation of the PWM signal with space vector modulation to activate six insulated-gate bipolar transistors (IGBTs) of a three-phase inverter. The experimental results are recorded with a sampling time of $100 \mu \mathrm{s}$.

5.1. Experimental Results via the UART Communication Port. The hardware modules used here are the aMG USB Converter-N and the aMG SQLite Data Server board. Two Simulink-generated codes are built to achieve the scalar control algorithm of the IM which are the target and the host codes. The target Simulink STM32F4-generated code shown in Figure 14 allows reading the incremental encoder information (rotor speed) for the PI regulator input. It forces the actual speed to reach its reference. It generates PWM signals using symmetrical SVPWM technique. Figure 14 shows that there are two parts: the Waijung Blockset (green color) and the developed code (light blue color). Waijung Blocksets used here are as follows:

(i) UART setup block for STM32F4 DISCOVERY + aMG F4 Connect $2+$ aMG USB ConverterN2 setting use (setup UART3 Baudrate 5000000 Pin $\mathrm{D} 8 / \mathrm{D} 9$ for $\mathrm{Tx} / \mathrm{Rx}$ ).

(ii) Target setup block used to setup STM32F4 in a Simulink model.

(iii) UART $\mathrm{Rx}$ and Tx receive and send UART information from/to host program (via aMG USB connect 2 and USB converter N2).

(iv) Basic PWM uses time 1 to generate 3 active high PWM signals

(v) Encoder Read uses built-in STM32F4 timer to interpret encoder data. However, the target model allows to read encoder channels $\mathrm{A}$ and $\mathrm{B}$ using pin B4 and B5, respectively, and output encoder position and count as binary data packet via UART Setup pin D8. 


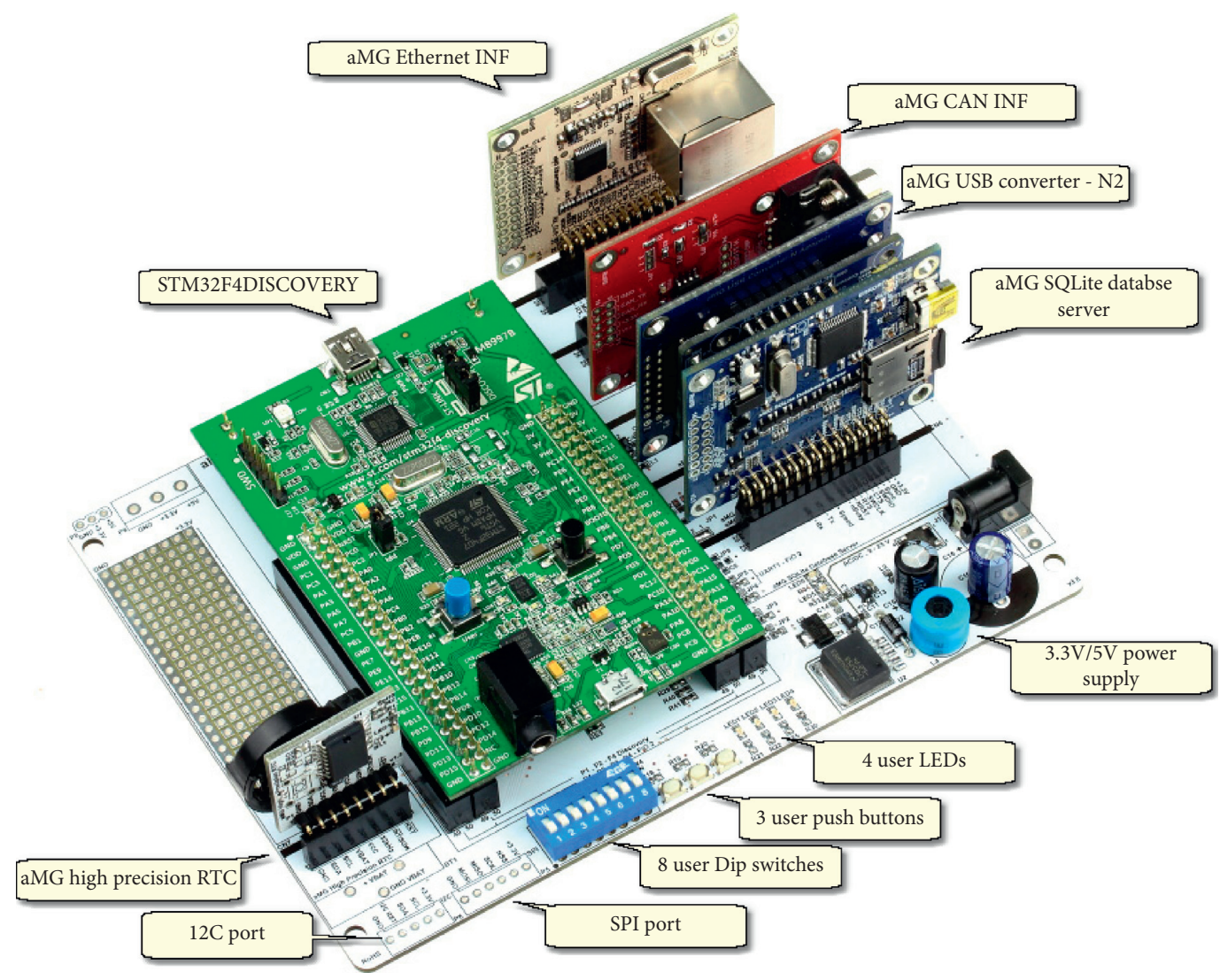

FIGURE 12: Low-cost high-performance DSP hardware with a variety of Plug-n-Play modules.

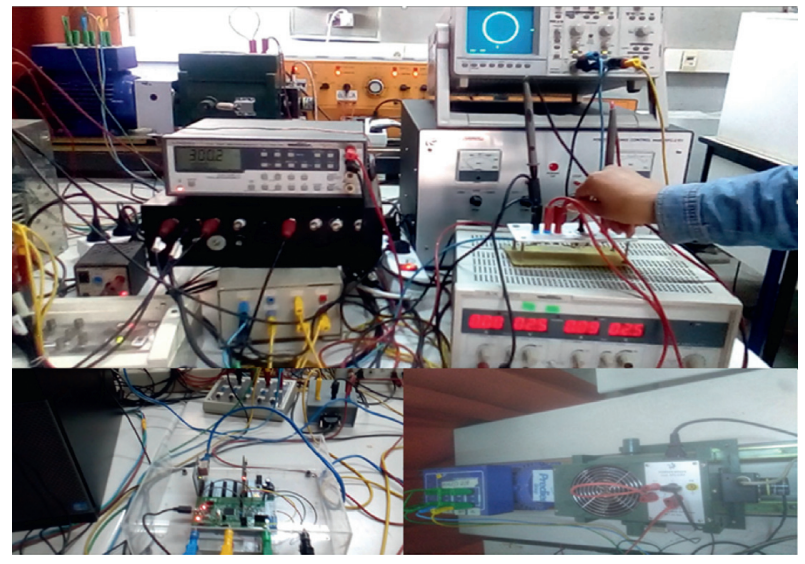

FIgURE 13: Experimental test bench.

Generated programs concern the incremental encoder, the symmetrical SVPWM, and the PI antiwindup controller. Figure 15 shows the encoder code developed to read the information from the incremental encoder and convert it into an angular velocity. Figure 16 shows the developed Simulink code to configure Timer 1 to generate $3100 \mu \mathrm{s}-$ period $(10 \mathrm{KHz})$ active high PWM signals to pin E9, E11, and $\mathrm{E} 13$ with percentage of $\mathrm{Ra}, \mathrm{Rb}$, and Rc duty cycle, respectively. Figure 17 shows the PI controller Simulinkgenerated code to be used within the antiwindup PI controller.
The host Simulink STM32F4 code is shown in Figure 18. This model is configured around 3 Waijung Blocksets to send set-point changes of speed, and the received binary data packet is displayed in real time as display and plot within the $\mathrm{COM} / \mathrm{UART}$ port and aMG Converter-N2 (USB-UART converter) hardware component channel $D$.

The performance and the accuracy of the designed real-time speed control of the IM are verified via two scenarios: the first scenario is done at step changing of the speed reference, where the second scenario is done at step changing of load torque under a constant reference speed.

5.1.1. Scenario 1: Reference Speed Change. This test is carried out to confirm the correctness and good performance of the antiwindup controller despite a large variation of speed reference. The reference speed variation crenels in $\mathrm{rad} / \mathrm{s}$ apply from zero, then 100, 120, 157, 150, and 80, and finally zero. The IM is operated here without the load. Figure 19 proves that the sensed speed pursues its reference in a perfect way, and the time response for each variation does not exceed $2 \mathrm{~s}$ without overshot. This implies that the antiwindup controller operates perfectly, and the whole program is well designed for the high-performance IM speed drive.

Because the IM is without the load, the slip pulsation is null, and the stator and rotor pulsations are equal. This is confirmed by Figure 20 showing the response of the stator pulsation $\omega_{\mathrm{s}}$ and the rotor speed noted here $\omega_{\mathrm{r}}$ for the above 


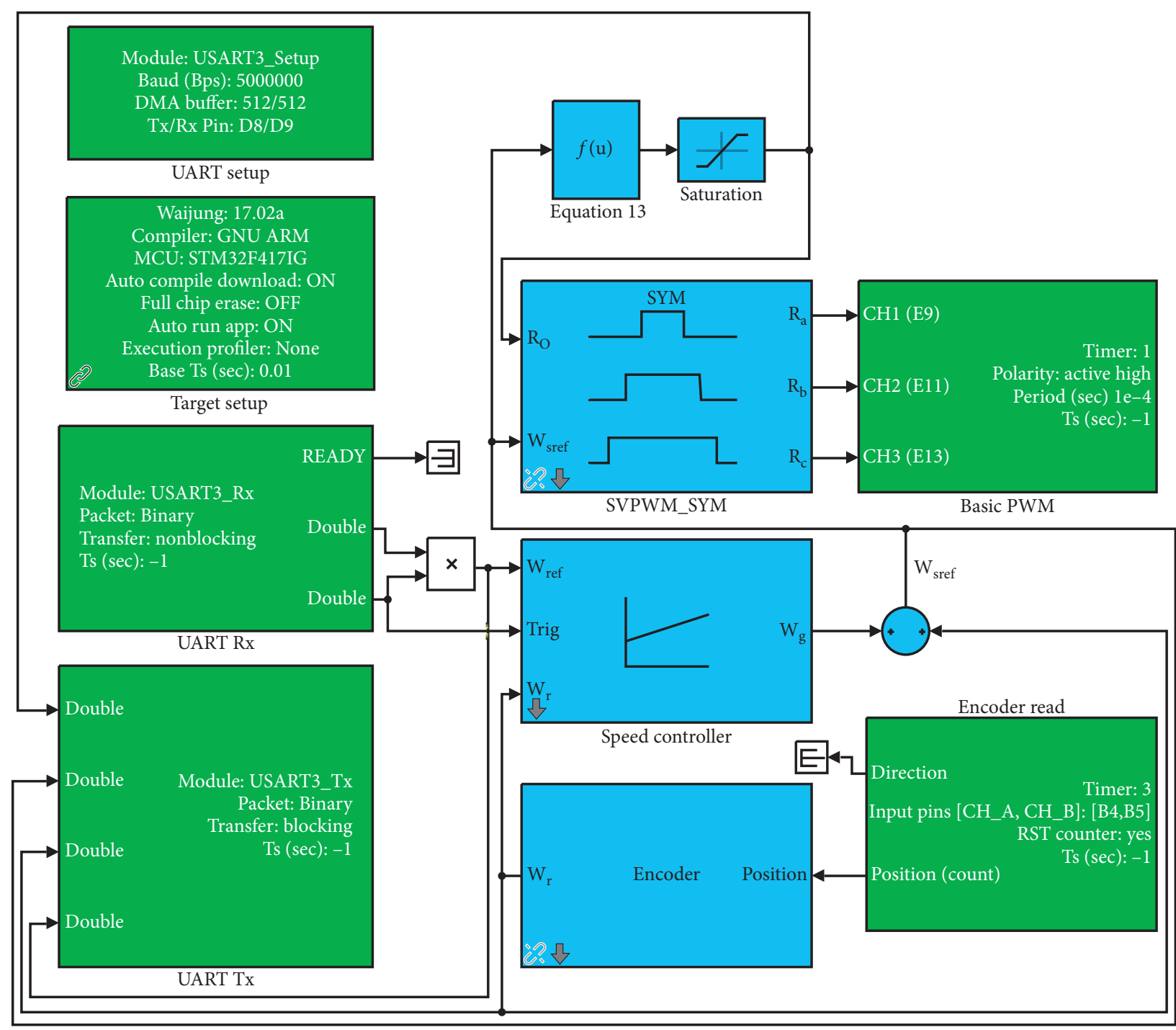

Waijung blockset

Figure 14: Target model for the implemented scalar control.

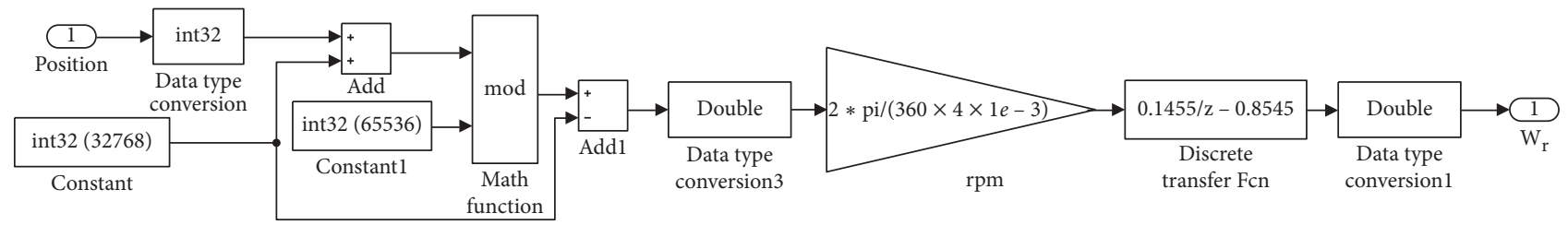

FIGURE 15: Simulink model for encoder target.

scenario. The stator pulsation varies parallel to the reference speed $\omega_{\text {ref }}$ and in proportionality with the stator voltage to maintain the $\mathrm{V} / \mathrm{F}$ constant. This rule is confirmed by Figure 21 that the ratio voltage varies from $65 \%$ for reference speed of $100 \mathrm{rad} / \mathrm{s}, 78 \%$ for $120 \mathrm{rad} / \mathrm{s}, 100 \%$ for $157 \mathrm{rad} / \mathrm{s}$ (synchronous speed), $98 \%$ for $150 \mathrm{rad} / \mathrm{s}$, and $52 \%$ for $80 \mathrm{rad} / \mathrm{s}$.
5.1.2. Scenario 2: Load Torque Change. These series of tests employ a nominal reference speed of $150 \mathrm{rad} / \mathrm{s}$ when applying step variations of load torque. Figure 22 presents the response of the rotor speed when the IM is driven in a closed-loop scalar control. This figure demonstrates that, for a large variation of load torque of four crenels as in simulation tests $(0,3,6.82,3$, and $0 \mathrm{Nm})$, the measured 


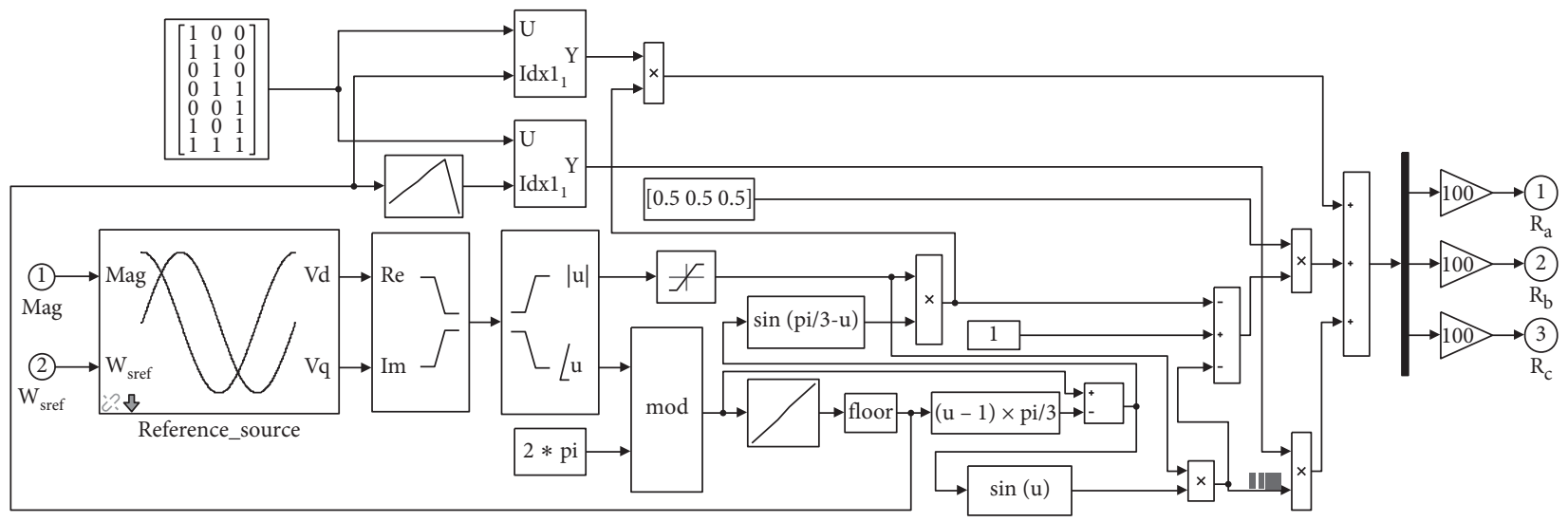

FIgURE 16: STM32F4-configured PWM.

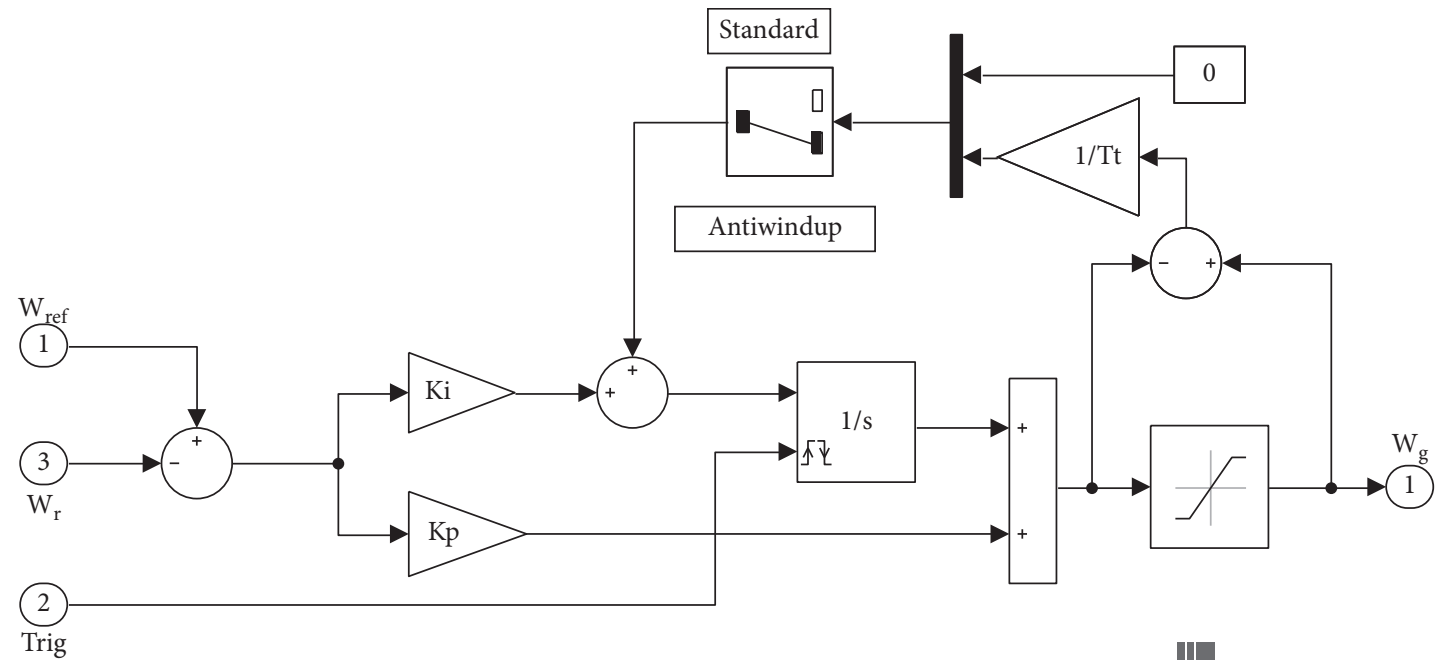

Figure 17: Antiwindup PI structure.

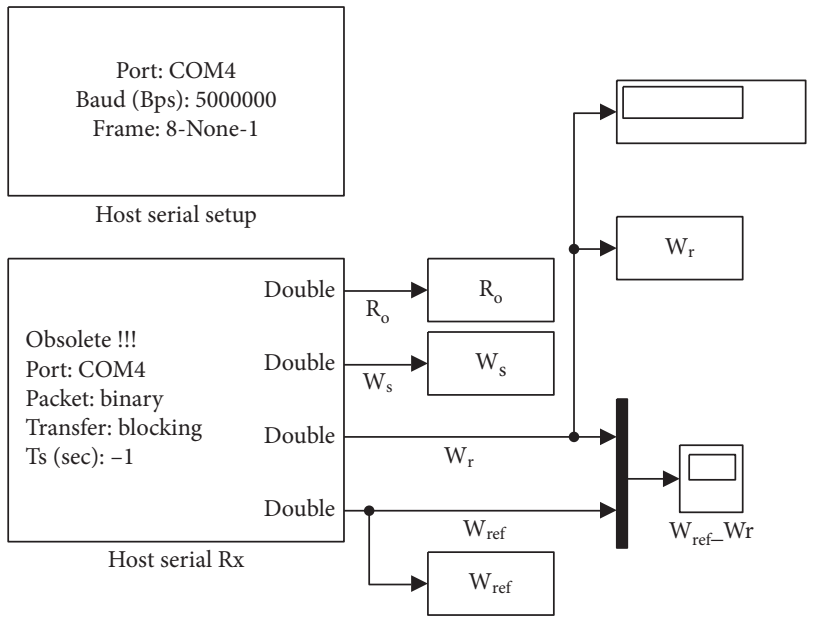

Host serial Tx

Port: COM4

Packet: binary

Transfer: blocking

Ts (sec): -1

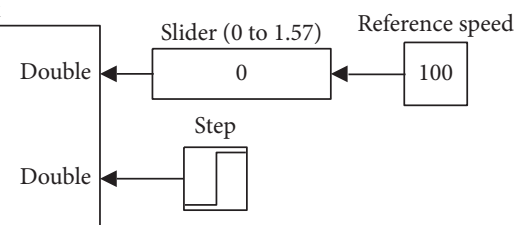

Figure 18: Host model for the implemented scalar control. speed is kept constant close to the reference. Figure 23 presents a zoom off Figure 22 in steady state operation proving that the overshot does not exceed $2.6 \%$, and the settling time is less than $2 \mathrm{~s}$ in nominal operation. Such performances prove that the antiwindup regulator PI operates correctly, and its parameters $\mathrm{Ki}$ and $\mathrm{Kp}$ are well designed. Besides, a fine consistency between the generated Simulink codes and the Waijung Blockset target for STM32F4 Discovery is proved. In addition, a better use of Waijung Blockset in electrical machines control applications.

The proprieties of the V/F control for the IM are well verified by Figures 24-27. Reverting to equations (11) and (12) that the electromagnetic torque is proportional to the square of the stator voltage and its frequency, these properties explain why the voltage ratio and the stator pulsation increase and decrease parallel to the load torque to keep rotor speed constant. The real-time response of the voltage ratio is shown in Figure 24. A zoom on this figure, Figure 25, proves that the ratio varies between $96.5 \%$ and $100 \%$ according to the load torque in respect to equation (12) $(100 \%$ in the nominal operating regime). The reference stator pulsation used to compute the stator voltage, 


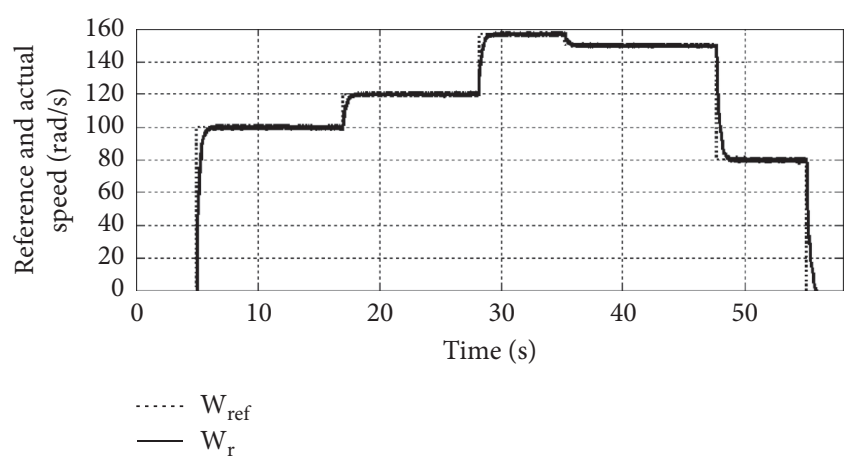

FIGURE 19: Speed response under the effect of reference speed changes.

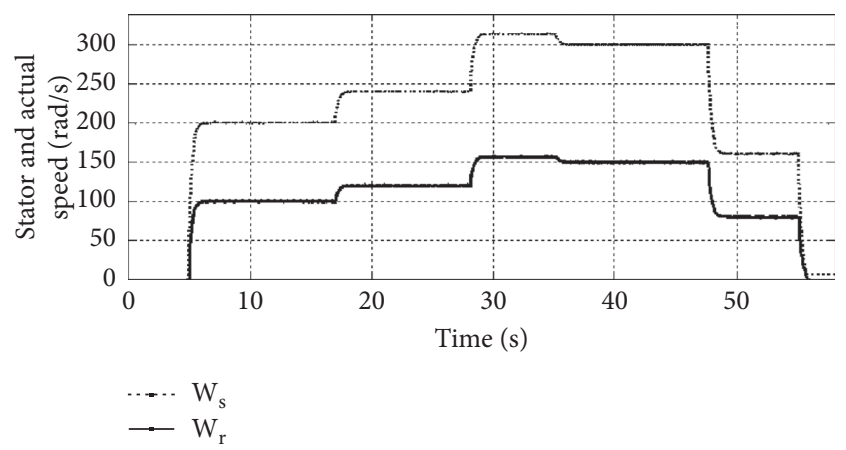

Figure 20: Stator and rotor pulsation responses under the effect of reference speed changes.

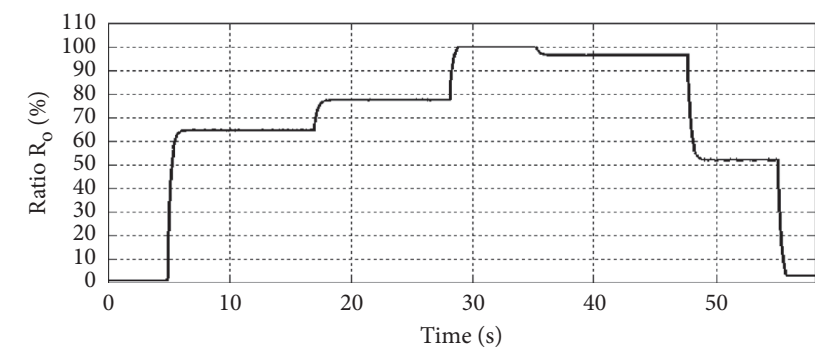

FIGURE 21: Voltage ratio response under the effect of reference speed changes.

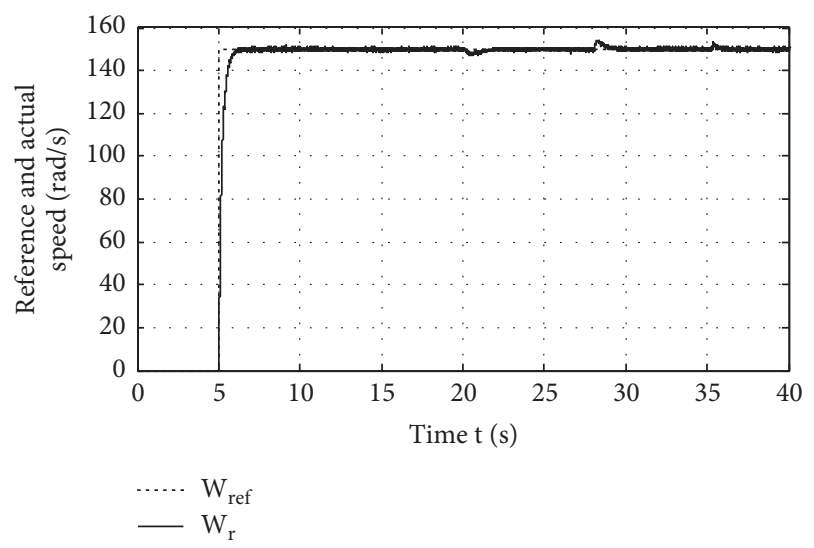

FIgURE 22: Speed response under load torque variation.

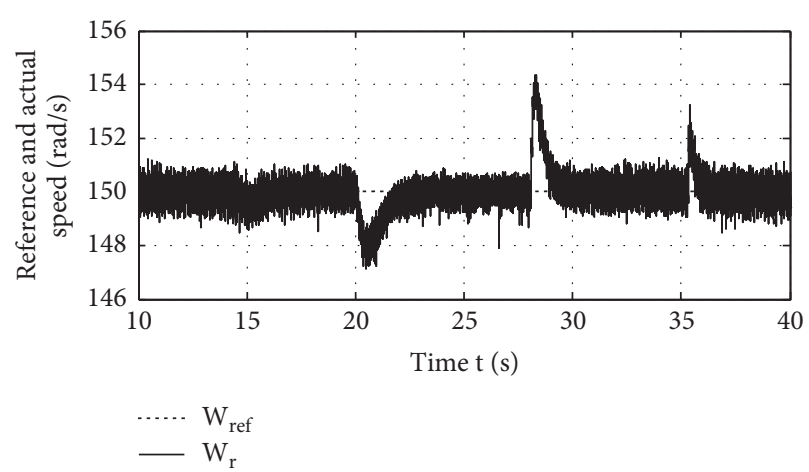

Figure 23: A zoom on measured speed.

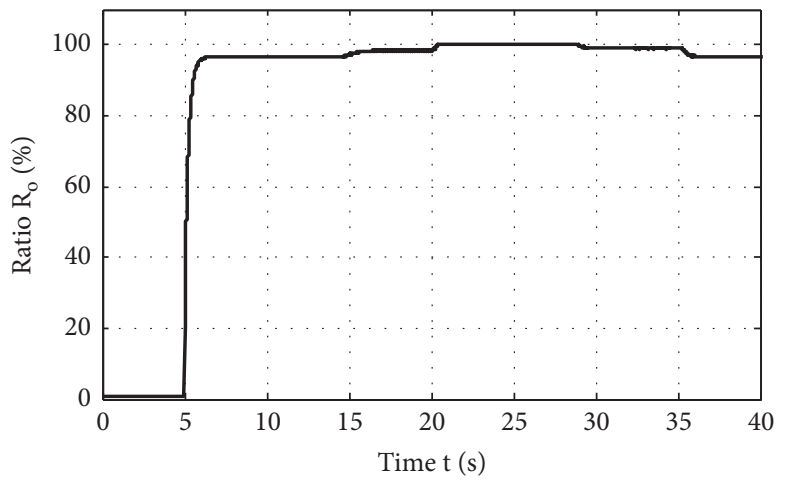

FIGURE 24: Voltage ratio response under load torque variation.

according to equation (12), is shown by Figure 26. A zoom on the last figure shown in Figure 27 denotes that such pulsation varies from $300 \mathrm{rad} / \mathrm{s}$ with no load torque to $331 \mathrm{rad} / \mathrm{s}$ in the nominal operating regime. The difference between the stator and rotor pulsation represents the slip pulsation, which is proportional to the torque (described by equation (11)) and proves the well regulation of the speed variable. It is obvious to observe that all obtained experimental results are incredibly close to simulation results. This finding proves the correctness and the accuracy of the real-time implementation of the proposed speed control hardware/software solution.

5.2. Experimental Results via Waijung WebPage Designer. Waijung WebPage Designer (W2D) is a set of Web tools dedicated to applications requiring monitoring and control on the Web in a simpler and faster way using the Waijung Blockset and Aimagin hardware. In other words, W2D is a compilation of web tools, such as HTML5, CSS, Javascript, JSON, jQuery, jQuery Mobile, SQLite, AJAX, and stream. The system also presents the automatic and manual control methods to stop or start the induction machine to avoid system failures. The hardware requirement for this application is cited as follows:

(i) STM32F4DISCOVERY

(ii) aMG F4 Connect 2+ Micro SD card

(iii) aMG Ethernet INF

(iv) aMG SQLite Database Server + Micro SD card 




Figure 25: A zoom on voltage ratio.

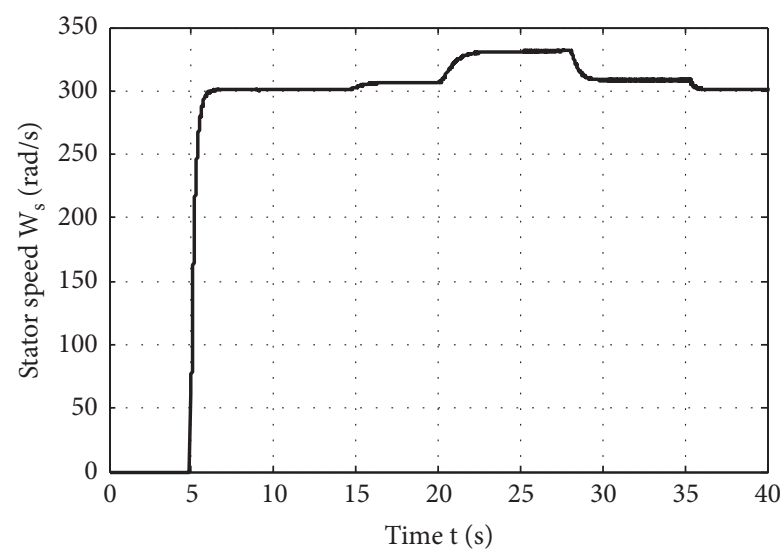

FIGURE 26: Stator pulsation response under load torque variation.

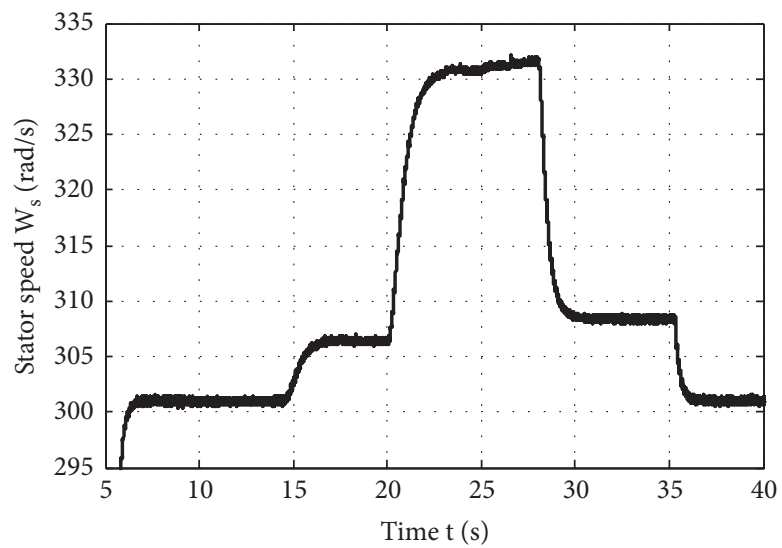

Figure 27: Zoom on stator pulsation.

The Micro SD card must be at least $4 \mathrm{~GB}$ so that it provides a data speed fast enough for communication with the MCU.

The Simulink/Matlab model used for web monitoring and control of the IM speed in closed-loop operation is shown in Figure 28. In addition to main previous programs (Encoder, SVPWM, PI controller and main Target Setup), it contains setup blocks for W2D. Inside the W2D Setup Subsystem (white color), it is grouped as five setup blocks. (i) Webserver Setup composed by three blocks: Ethernet Link Setup, Ethernet Application Setup, and Http Server Setup

(ii) UART Setup uses UART Module 6 for $\mathrm{Tx} / \mathrm{Rx}$ (to talk to aMG SQLite Database Server Module)

(iii) SQLite Database setup uses Port UART6 (interface with aMG SQLite Database Server) 


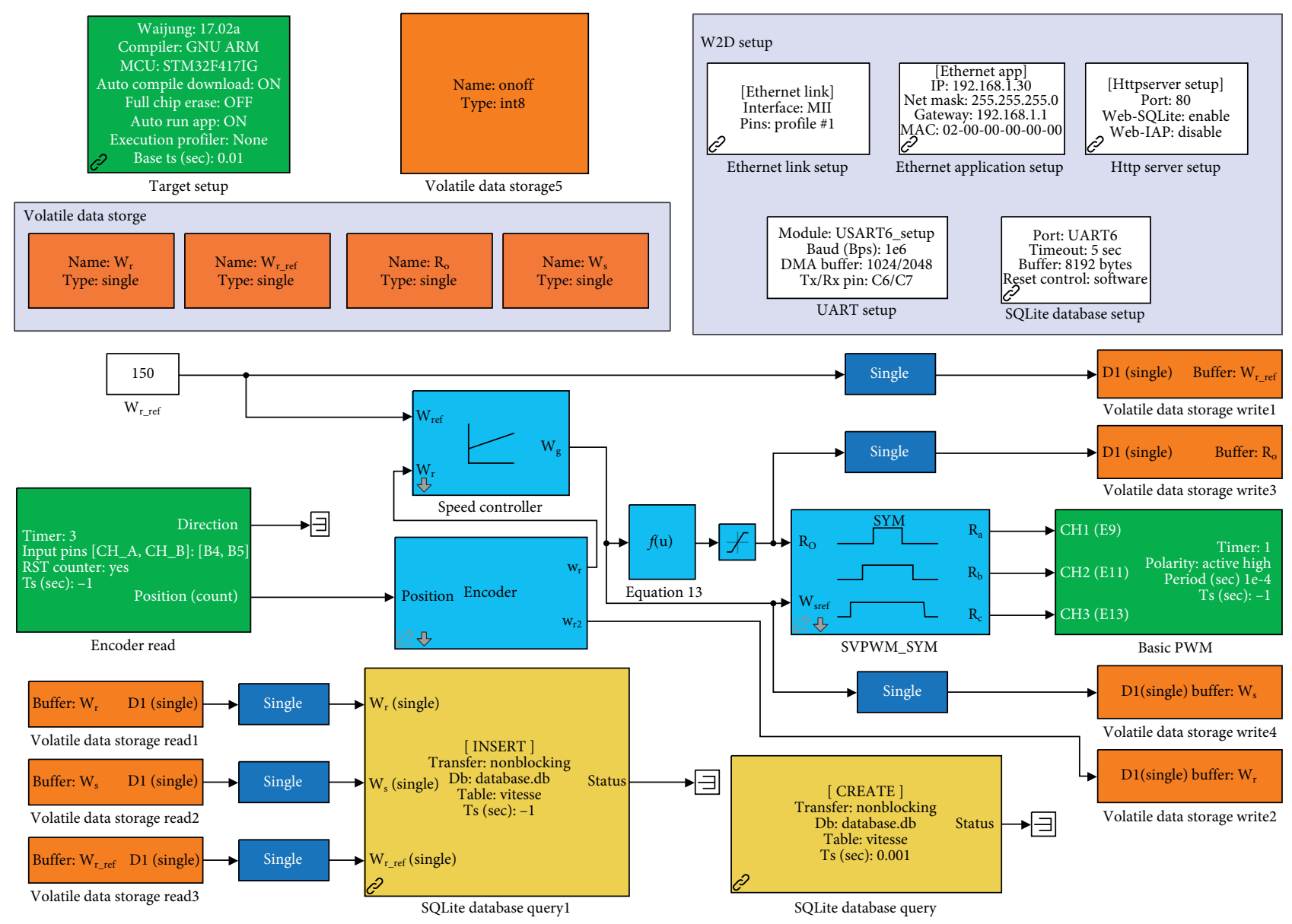

FIGURE 28: Simulink model of speed monitoring and control for IM with Waijung W2D.

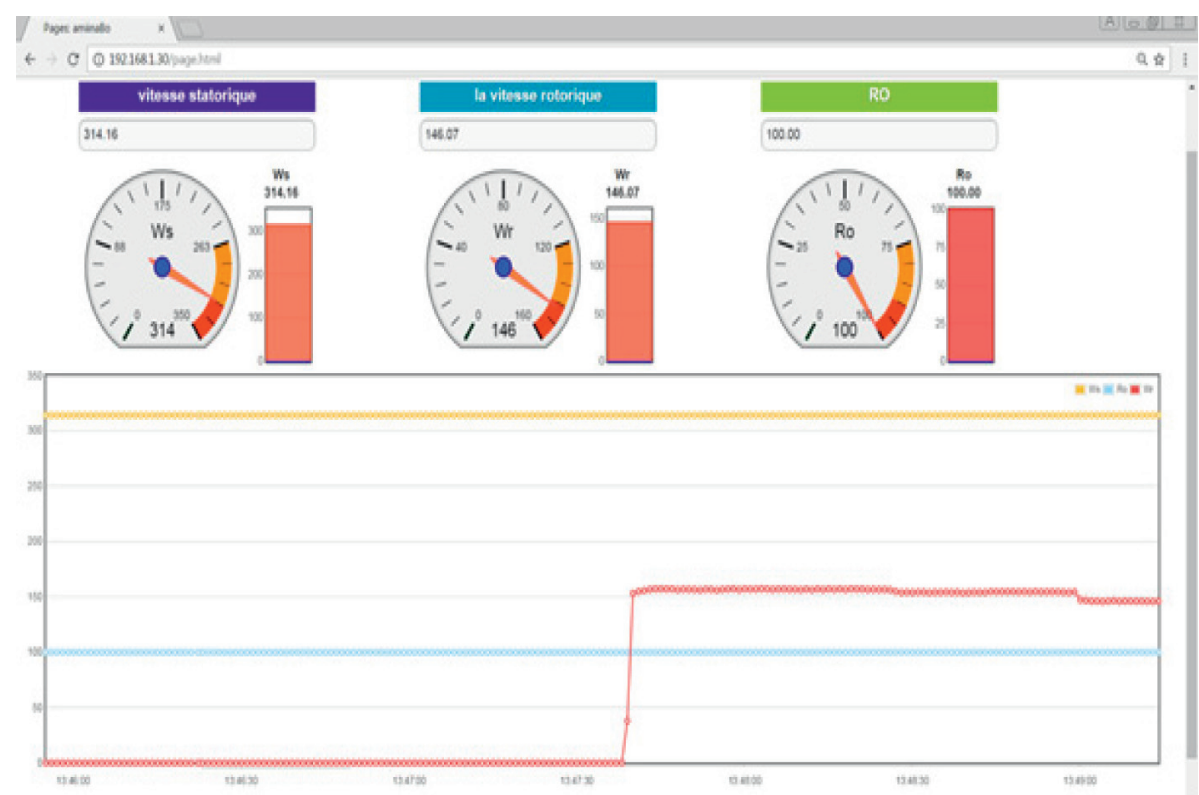

FIgURE 29: Web-based monitoring and control. 
The volatile data storage (orange color) is used to store data for another use of the model. Values stored in data storage are mapped for web access. Mapped variables are set to Read Only or Write/Read. The SQLite database query (yellow color) is configured for communication between Web Interface and Webserver System.

Using the Waijung WebPage Designer (W2D) tool, we created a web interface for monitoring values (rotor speed $\mathrm{Wr}$, stator speed Ws, and voltage ratio RO) on the MCU webserver and displaying on web browser as text and digital values, Ws, Wr, and Ro. Figure 29 shows an illustrative example of the results on the web. The rotor speed value is in red color, and the voltage ratio and stator pulsation are presented in blue and yellow color, respectively. The purpose here is to reveal the scientific and technological feasibility of the web monitoring and control since the performance of the algorithm is verified in the previous part. We attached with this paper a sequence video summarizing these experimental results.

\section{Conclusion}

In this work, a technical approach for the monitoring and control of the IM speed driven under V/F control is introduced and carried out via simulation and experimental results using a Waijung Blockset and aMG hardware around an STM32F4 Discovery board.

The proposed control structure is strengthened by a solid antiwindup PI regulator and supported by the association of the STM32F4-Waijung Blockset which constitutes a perfect and promising platform for many industrial applications due to the rapid and the simple prototyping and the low-cost design. Please confirm that this is your intended meaning. Indeed, not only it eliminates the use of the voltage and the current sensors but also it removes use of hard programming languages. The estimated cost of the entire installation (STM32F4 and Aimagin hardware components) does not exceed 400 USD, while the estimated cost of a similar prototype using dSPACE 1104, for example, exceeds 12,000 USD.

Simulation and experimental tests carried out for speed reference changes and load torque prove the robustness of the proposed solution, where the PI controller admits a superior response even in severe operating regimes.

\section{Data Availability}

The data used to support the findings of this study are included within the article.

\section{Conflicts of Interest}

The authors declare that they have no conflicts of interest.

\section{Acknowledgments}

Funding for this work was provided by the Research Laboratory ERCO (Energy, Robotics Control and
Optimization), National Institute of Applied Sciences and Technology (INSAT) of Tunis, Tunisia.

\section{References}

[1] M. P. Sruthi, C. Nagamani, and G. Saravana Ilango, "An improved algorithm for direct computation of optimal voltage and frequency for induction motors," Engineering Science and Technology, an International Journal, vol. 20, no. 5, pp. 1439-1449, 2017.

[2] C. Liu and Y. Luo, "Overview of advanced control strategies for electric machines," Chinese Journal of Electrical Engineering, vol. 3, no. 2, pp. 53-61, 2017.

[3] M. A. Hannan, J. A. Ali, A. Mohamed, and A. Hussain, "Optimization techniques to enhance the performance of induction motor drives: a review," Renewable and Sustainable Energy Reviews, vol. 81, no. 2, pp. 1611-1626, 2018.

[4] K. Rakesh, D. Sukanta, and A. Kumar, "Comparative assessment of two different model reference adaptive system schemes for speed-sensorless control of induction motor drives," IET Electric Power Applications, vol. 10, no. 2, pp. 141-154, 2016.

[5] A. Khedher and M. Faouzi Mimouni, "Sensorless-adaptive DTC of double star induction motor," Energy Conversion and Management, vol. 51, no. 12, pp. 2878-2892, 2010.

[6] M. Jannati, S. A. Anbaran, and S. H. Asgari, "A review on variable speed control techniques for efficient control of single-phase induction motors: evolution, classification, comparison," Renewable and Sustainable Energy Reviews, vol. 75, pp. 1306-1319, 2017.

[7] S. Andrew, G. Shady, A. Matthew, and F. John, "Improved method for the scalar control of induction motor drives," IET Electric Power Applications, vol. 7, no. 6, pp. 487-498, 2013.

[8] M. P. Juan and V. D. Edilberto, "Implementation of V/F scalar control for speed regulation of a three-phase induction motor," in Proceedings of the 2016 IEEE Andescon, IEEE, Arequipa, Peru, October 2016.

[9] A. Hmidet, R. Dhifaoui, and O. Hasnaoui, "A new direct speed estimation and control of the induction machine benchmark: design and experimental validation," Mathematical Problems in Engineering, vol. 2018, Article ID 9215459, 10 pages, 2018.

[10] S. Tole, N. I. Nik Rumzi, and J. Auzani, "A review of direct torque control of induction motors for sustainable reliability and energy efficient drives," Renewable and Sustainable Energy Reviews, vol. 32, pp. 548-558, 2014.

[11] I. M. Alsofyani and N. Idris, "A review on sensorless techniques for sustainable reliability and efficient variable frequency drives of induction motors," Renewable Sustainable Energy Review, vol. 24, pp. 111-121, 2013.

[12] Y. Oguz and M. Dede, "Speed estimation of vector controlled squirrel cage asynchronous motor with artificial neural networks," Energy Conversion and Management, vol. 52, no. 1, pp. 675-686, 2011.

[13] B. Mohamed, L. Chrifi-A, N. V. Alessandro, M. Ch, and D. Said, "Online robust estimation of flux and load torque in induction motors," The International Journal of Advanced Manufacturing Technology, vol. 94, no. 5-8, pp. 2703-2713, 2018.

[14] B. Singh and S. Shukla, "Induction motor drive for PV water pumping with reduced sensors," IET Power Electronics, vol. 11, no. 12, pp. 1903-1913, 2018.

[15] I. Boldea, "Control issues in adjustable speed drives," IEEE Industrial Electronics Magazine, vol. 2, no. 3, pp. 32-50, 2008. 
[16] T. H. dos Santos, G. Alessandro, S. A. O. da Silva, and S. Marcelo, "Scalar control of an induction motor using a neural sensorless technique," Electric Power Systems Research Elsevier journal, vol. 108, pp. 322-330, 2014.

[17] A. Pugachev, "Efficiency Increasing of Induction Motor Scalar Control Systems," in Proceedings of the 2017 International Conference on Industrial Engineering, Applications and manufacturing (ICIEAM), St. Petersburg, Russia, May 2017.

[18] G. R. Markadeh, E. Daryabeigi, C. Lucas, and M. A. Rahman, "Speed and flux control of induction motors using emotional intelligent controller," IEEE Transactions on Industry Applications, vol. 47, no. 3, pp. 1126-1135, 2011.

[19] K. S. Anup, M. K. Nallapaneni, P. Swapnajit, and K. Vinay Reddy, "Speed control of 3-phase induction motor fed through direct matrix converter using GSPWM technique with unity input power factor," in Proceedings of the 2016 international conference on electrical power and energy systems (ICEPES), pp. 420-425, IEEE, Bhopal, India, Bhopal, India, December 2016.

[20] R. Maamouri, M. Boussak, and F. M'Sahli, "Sliding mode observer sensorless vector controlled induction motor drive with anti-windup PI speed controller," in Proceedings of the XXII International Conference on Electrical Machines (ICEM), IEEE, Lausanne, Switzerland, September 2016.

[21] K. Sinan, O. Tolga, and O. Yuksel, "Design and implementation of Dspic33fj32mc204 microcontroller-based asynchronous motor voltage/frequency speed control circuit for the ventilation systems of vehicles," Measurement and Control, vol. 52, no. 7-8, pp. 1039-1047, 2019.

[22] D. Aziz and L. Ahmed, "Real-Time simulation and analysis of the induction machine performances operating at flux constant," (IJACSA) International Journal Of Advanced Computer Science And Applications, vol. 5, no. 4, pp. 9-64, 2014.

[23] C. Anurag, G. Deepam, L. S. Sudha, and A. Aparna, "Condition monitoring and fault diagnosis of induction motors: a review," Archives of Computational Methods in Engineering, vol. 26, pp. 1221-1238, 2019.

[24] R. Narayan Dash, "Condition monitoring of induction motors:- a review," in Proceedings of the International Conference On Signal Processing, Communication, Power And Embedded System (SCOPES), IEEE, Paralakhemundi, India, October 2016.

[25] K. Adlen, M. Abderrezak, K. Ridha, and B. Mohamed, "Realtime safety monitoring in the induction motor using deep hierarchic long short-term memory," The International Journal of Advanced Manufacturing Technology, vol. 99, no. 9-12, pp. 2245-2255, 2018.

[26] S. Manivannan, S. Veerakumar, P. Karuppusamy, and A. Nandhakumar, "Performance analysis of three phase voltage source inverter fed induction motor drive with possible switching sequence execution in SVPWM," The International Journal of Advanced Research in Electrical, Electronics and Instrumentation Engineering, vol. 3, no. 6, pp. 1081-1104, 2014.

[27] A. Oteafy and J. Chiasson, "A study of the lyapunov stability of an open-loop induction machine," IEEE Transactions on Control Systems Technology, vol. 18, no. 6, pp. 1469-1476, 2010.

[28] A. Hmidet and O. Hasnaoui, "Waijung blockset-STM32F4 environment for real time induction motor speed control," in IEEE 5th international congress on information science and Technology (CiSt), IEEE, Marrakech, Morocco, October 2018.

[29] Aimagin product, https://www.aimagin.com.
[30] Waijung Web Page Designer (W2D), http://waijung.aimagin. com. 